\title{
Innovation Research of Social Management for Large and Medium Sized Hydropower Project Resettlement
}

\author{
Xiao Cong ${ }^{1}$, Chen Jian-xi ${ }^{1}$, He Ming-zhang ${ }^{2}$, Ren Rong ${ }^{1}$, Dong Kai-ling ${ }^{3}$, \\ Zhang Xue-mei ${ }^{1 *}$ \\ ${ }^{1}$ Chengdu University Chengdu Sichuan 610106 \\ ${ }^{2}$ The Yalong River Hydropower Development Co., Ltd. Chengdu Sichuan 610056 \\ ${ }^{3}$ Chengdu industry Career Technical College Chengdu Sichuan 610213
}

\begin{abstract}
This paper discusses migration, hydropower project migration and the ways of hydropower project resettlement, analysis social management issues of Chinese large and medium-sized hydropower project resettlement, discusses the ways of social management innovation of Chinese large and medium-sized hydropower engineering migration, such as strengthen the migration policies, laws and regulations publicity, straighten out the resettlement management system, strengthen the policies and regulations training of migration cadres, construction of social security system for reservoir migrants.
\end{abstract}

Keywords: large and medium-sized hydropower project resettlement social management innovation.

\section{Migration And Hydropower Projects Resettlement}

\subsection{Migrants}

Migration is a general term for the migration of the population in different regions, including the migration of population and the migration activities. And it divide into two kinds: one is move to a permanent settlement of foreign countries, and the other is the migration of population organized, a large number of cases. This article refers to the following large numbers of organized migration. living in a place of the population and then moved to live permanently in the field of behavior, the object of this paper is called "migration".

Migrants are divided into active and passive migrants. Active migration means they would like to move from the original residence to a another residence. Passive migration means for the economic development, the country occupant the land mandatory, migrants have to move to a place out the scope of influence. Migrants themselves are not the initiative to move, but have to move. The research object of this paper is limited to passive migration.

\subsection{Hydropower Projects Resettlement}

Due to the water conservancy project and government arrangement, people have to move to another regions. Hydropower Projects Resettlement belongs to passive migration.

\subsection{Resettlement Mode of Hydropower Projects}

\subsubsection{According to the Distance from the Reservoir, Resettlement Divided into Place to near behind} and Place to far two ways.

Place to near behind means people moved out of the flooded area (including the bank collapse and landslide) and building house of the reservoir near the migration line from the outside location.

Place to far means people moved out of the flooded area (including the bank collapse or landslide) and the hydropower project is far from the rest of the resettlement housing location.

\subsubsection{According to the Choice of the Migration of the Production Materials, Resettlement Divided into Soil Resettlement and no Soil Resettlement.}

Soil resettlement refers to the relocation and resettlement way, after sufficient land circulation, the main agriculture resettlement way to solve the problem of existence after the relocation. 
No soil resettlement refers to the relocation of migrants no longer depend on land as the main ways of production and subsistence, but depend on other ways of production or operation to solve the problems of resettlement after relocation.

\section{The Social Management Problems of Chinese Large and Medium Sized HYDROPOWER PROJECT}

Since the founding of new China, at the end of 2014, Chinese has built the hydropower engineering 98,002 , hydropower engineering migrants accumulated more than 25 million people, the total reservoir capacity of 8396 billion cubic meters, has had the tremendous comprehensive benefits in flood control, power generation, water supply, irrigation which have a strong impetus to the economic and social development, this hydropower engineering get rid of thousands of year of flooding and drying disaster to the country and people, and make a property safety of a serious threat, fulfill to the needs of social and economic development.

Although our country make lots of rules and regulations to make sure the hydropower project resettlement work smoothly and hydropower engineering migration sustainable development, in the past there are serious " attach importance to engineering in hydropower project, light migration" concept, under such a social background, the complexity of hydropower project resettlement works lack of understanding, social management inevitably bring some new problems.

With the development of the market economy and the improvement of the consciousness of the rights of migrants, migrants requires adjustment compensation standard, share the benefit of Water Conservancy Hydropower Project, pursuit of long-term interests of compensation by the market rules, the rule of law and interest balance mechanism; part of the migrants meet the product and living difficulties, the contradiction of the employment, income decline, lack of long-term livelihood security after resettlement; some resettlement area water circuit infrastructure construction, medical and education are not complete; some local support measures are not quite in place, the effect is poor, migrants have to worry about some of the migration problems; and migrants are difficult to integrate into local society, marginalized by society, few migrants suffer long-term poverty and secondary poverty, bring very seriously psychological dependence or resentment; very poor migrants formed major diseases, lack of education, pension, disability, natural disaster problems; reservoir in non voluntary migration gave birth to a few special migrant class psychological dependence, asked the government arranged everything, blind pursuit does not conform to the policies of individual interests; the ruling ability and the management level of some local governments is not suit, the legitimate rights and interests of minority migrants have not been guaranteed; parts of regions environmental polluted and destructed, which effect on the quality of environmental migrants, and so on.

\section{Social Management InNOVATion}

\subsection{Social Management}

Social management is the government and social organizations to promote the social system operate smoothly, on the part of the social system, the social life in different fields and social development of all aspects of organization, coordination, guidance, specifications, supervision and correction of social failure process. Social management in a broad area refers to specialized agencies by the members of the society economic, political and cultural affairs management; in a narrow area refers only to under certain conditions, the department authorized not to be classified including economic, political and cultural management of public affairs.

The basic tasks of social management include coordinating social relations, regulating social behavior, solving social problems, resolving social conflicts, promoting social justice, dealing with social risks, maintaining social harmony and so on. social management first is to promote social autonomy, second is to resolve the contradiction between rational economic man and irrational social people, third is to regulate social behavior, forth is to monitor and monitor the social behavior of social benefits.

\subsection{Social Management Innovation}

Social management innovation refers to the existing social management condition, use of existing resources and experience, on the basis of political, economic and social development trend, especially the own social rules and social management and related concepts and standardize operation, studying and using new social management idea, knowledge, technology, method and mechanism, alteration, to 
improve and reform the traditional management mode and the corresponding management mode and method, construction of new social management mechanism and system, in order to achieve the new goal of social management activities or the activities of the process. Social management innovation is the activities to manage social existence as the premise, the purpose is to make the society to form a better order, resulting in a more ideal political, economic and social benefits.

\section{The InNovation Research of Social Management of LARge ANd Medium Sized Hydropower Projects ResetTlement in China}

\subsection{Strengthen Migration Policies and Regulations Publicity}

The construct important meanings of the water conservancy and hydropower project should be vigorously promoted by the migration work, improve the public awareness of the importance of the construction project of migration, to make sure migrants consciously obey the national economic and social development needs of the overall situation; promote national policy, migration policy, public resettlement scheme, compensation standard, funds management and use, for migrants timely understanding of migration policies and regulations of the state; publicize the party and the government on migration care as well as a series of preferential policies to help migrants development taken to thinking; legal education, strengthen the knowledge of migration law publicity and education of the masses through the normal channels, legal migration channels to reflect the wishes, demands and opinions to promote the reservoir resettlement; small family homes, we care spirit, fully affirmed them for water conservancy and hydropower project construction. Through strengthening the propaganda work, guide the masses to understand and support the migrant work.

\subsection{Straighten Out the Migration Management System}

To figure out the country's migration administrative agencies as soon as possible, and give the formulation of administrative management mechanism of migration studies policies, laws and regulations, and supervise their implementation, examination, approval of the plan outline of resettlement of migrants, migration resettlement planning and supervising the implementation, organization of project resettlement funds of inspectors, organization for the acceptance of the resettlement project, to engage in planning to design and monitoring of migrants of the units and individuals qualifications management, and other functions for the migration work to implement the whole process management. According to the situation of our country, we should regulate the setting and management of the migration institutions of all provinces, autonomous regions and municipalities directly under the central government as soon as possible. According to obey the mission, to facilitate command and coordination, to meet the economic development of migration principles, establish and improve the resettlement management organization, and incorporated into the sequence of administration, provide to ensure funding for management, strengthen administrative functions, improve the migration authorities of the organization, coordination and management ability, ensure the smooth implementation of the resettlement work.

\subsection{Strengthen Policy and Regulation of the Migration Cadres Training}

Attaches great importance to the training of cadres migration, in particular, strengthen policy and regulation of the migration cadres training, establish a strong political, hard style, high level policy migration management team, to ensure the migration policies, laws and regulations has been effectively implemented. The implementation of migration professional qualification management, implement professional qualifications and the qualifications of management for engaging in resettlement planning and design, supervision on resettlement, resettlement monitoring and evaluation of personnel and units, through training, examination, registration, and a series of measures, and gradually establish a high-quality cadres migration professional team.

\subsection{Increase Investment in Migration Project Support}

Multi-channel, multi-level strengthen the resettlement project support, and promote the project planning to support the implementation and speed up the pace of reservoir migrants to take off deficient to become rich, the production and living standards of the migrants as soon as possible to achieve the average level of the resettlement area to the country farmers. One is to fully implement the late stage support policy, late support fund, fund collection area, to ensure the full and timely collection of relevant funds to support the latter storage. Second is to do a good job docking project support planning and special planning of the existing government departments, continue to strengthen the province now special funds of reservoir area and resettlement area tilt. Third is to actively expand 
the resettlement project support funding sources, continue to adhere to the "who benefits, who bears" principle, through the increase of the hydro electricity price, from the benefits of hydropower project withdrawing funds increase investment migration program support. Fourth is to strengthen the use and management of migrant projects to support the use of funds, to protect the safety of funds, to give full play to the effectiveness of funds.

\subsection{Establishment of Social Security System for Reservoir Resettlement}

Social security is the country or the government as the main body, in accordance with the law, through the redistribution of national income give material help to solving citizens who temporary or permanent loss of ability to work or other reasons that make life difficult. The government depends on the financial means to provide social security system for migrants, to guarantee the basic life of reservoir resettlement, enhance the ability to economic adaptability of migrants, guarantee their economic development. It guarantees that members of society have a sense of security, medical care security; It guarantees the basic living and reemployment of the unemployed; It guarantees temporary or permanent loss of labor ability to get material help and social services; It guarantees that the poor get social benefits or subsidies. Therefore, to provide a social security system for reservoir migrants, it to ease the conflict between members of the community, and resolve social risks, make social stability.

\section{REFERENCE}

Cai Meng-sheng, Wei Yong, China dream of reservoir migration: building a better and happier life, Lao Qu Jian She, 2014, (18):35-37

Song Yong, Concept and classification of Hydropower Project Resettlement, Heilongjiang Science and Technology of Water Conservancy2013,( 9 ) :186-188

Liang Fu-qing, Thoughts and Countermeasures on the management of social stability of reservoir resettlement, Journal of China Three Gorges University (Humanities \& Social Sciences) 2014,(1)

FANG Chang-rong, Current situation and development of resettlement management system for large and medium sized hydropower projects, Yangtze River, 2013(12):42-45

Zhu Tian-shu, Analysis and Countermeasures on the stability of reservoir resettlement, Henan Water Resources \& South-to-North Water Diversion, 2011,(19):25-27

Wang Zhen-tao, Guo Dong-qin, Research on the moral issues of reservoir resettlement in China. Journal of Yangtze Normal University, Journal of Yangtze Normal University, 2011, (6):60-63

Wei Xian-chao, Wu Zhuang-hai, Problems and treatment measures of reservoir resettlement, Pearl River, 2010,(5):3-6

Yin Hai-bo, Economic Analysis on asymmetric information of reservoir resettlement, Journal of Economics of Water Resources, 2010,(6):20-22

He Jian-yuan, Reservoir resettlement management and social and economic coordinated development mechanism, Water Resources Planning and Design, 2008,(3):9-12

Li Dan, Sun Ai-fen, The particularity of hydropower resettlement in Ethnic Minority Areas -- a survey of ethnic minorities in Sichuan, Heilongjiang National Series, 2007,(4):18-20

Sun Zhong-gen, Yang Wen-jian, Discussion on the establishment of social security system for reservoir resettlement, Yangtze River, 2007, (6):93-95

\section{Authors' Biography}

Correspondence author Zhang Xue-mei (1965-), female, doctor, Professor, master tutor, Chengdu University Professor, main research direction: enterprise management. Published papers 54, presided over the provincial (Department) level research projects 24, the main research 18; the publication of monographs and teaching materials 8 .

Author Xiao Cong (1985-), male, master, assistant researcher, main research direction: enterprise management, published 3 papers, participate in research projects 15, participate in the preparation of 2 works.

This paper is one of the research results of Sichuan provincial science and Technology Department of the soft science project "based on the livelihood of the people" perspective of the large and medium sized hydropower project resettlement social management innovation, research (project number: 2014ZR0127) 